\title{
Impact of physical activity and fitness on the level of kinesiophobia in women of perimenopausal age
}

\author{
Mariola Saulicz ${ }^{1}$, Edward Saulicz ${ }^{2,3}$, Andrzej Knapik ${ }^{4}$, Pawel Linek², Jerzy Rottermund ${ }^{5}$, \\ Andrzej Myśliwiec², Tomasz Wolny 2,3 \\ ${ }^{1}$ Department of Physiotherapy in Internal Organ Diseases, The Jerzy Kukuczka Academy of Physical Education, Katowice, Poland \\ 2Department of Kinesitherapy and Special Methods in Physiotherapy, The Jerzy Kukuczka Academy of Physical Education, Katowice, \\ Poland \\ ${ }^{3}$ The Academy of Business, Dąbrowa Górnicza, Poland \\ ${ }^{4}$ School of Health Sciences, Silesian Medical University, Katowice, Poland \\ ${ }^{5}$ Department of Physiotherapy, High Administration School, Bielsko-Biała, Poland
}

\begin{abstract}
To determine the impact of physical activity and fitness on the level of physical activity barriers (kinesiophobia) in women of perimenopausal age, the study included 105 women between the ages of 48 and 58 . A Baecke questionnaire was used to evaluate physical activity and a modified Fullerton test was used to evaluate the fitness level. The level of kinesiophobia was assessed using the Kinesiophobia Causes Scale questionnaire.

A low level of habitual physical activity has a negative impact on the values of Biological Domain $(r=-0.581)$, Psychological Domain $(r=-0.451)$, and on the Kinesiophobia Cause Scale total score $(r=-0.577)$. Lower physical activity expressed by a lower score in the Fullerton test also has a negative impact on the level of kinesiophobia. Upper body flexibility $(r=-0.434)$ has the strongest influence on the Biological Domain, whereas upper body strength $(r=-0.598)$ has the greatest impact on the Psychological Domain. A low level of upper body strength also has the greatest impact on the Kinesiophobia Cause Scale total score $(r=-0.507)$.

Low levels of physical activity and fitness in women of perimenopausal age favour kinesiophobic attitudes and thereby increase the level of barriers against undertaking physical activity.
\end{abstract}

Key words: perimenopausal age, kinesiophobia, physical activity, fitness.

\section{Introduction}

From a human health needs' point of view, the greatest threat to the development of a technical civilisation is a decrease in adaptive potential. This is a result of less demanding requirements of the environment with regard to humans' natural physical activity, which includes both walking locomotion and a broad range of locomotion, to ensure material existence. Maintenance of one's adaptive skills on an optimal level leads to supplementing the activity deficit in relation to biological needs. The most commonly used forms of physical activity are characterised by direct usability and aim to increase or maintain the fitness level. However, current studies suggest that during an average week of the year, up to $60 \%$ of adults in Europe do not undertake any physical activity of this type [1]. This worrying trend has already become permanent as recent studies conducted in 2013 also revealed that $59 \%$ of the adult population in Europe either did not undertake any form of physical activity or did it very rarely in their leisure time [2]. Studies with the use of an accelerometer have revealed that in Canada, only $15 \%$ of adults are physically active at the recommended health level [3]. Despite publicity in the media of the importance of physical activity for health, up to $40 \%$ of Europeans indicate that physical activity is not interesting for them and they prefer different types of activity during their leisure time [1]. Among 686 female residents of Madrid examined in the study carried out between March and June 2009, 82.7\% are characterised by such a low physical activity in their leisure time that they are in fact included in the category of those who lead a sedentary life, and this percentage is significantly greater in comparison to men (69.6\%) [4]. Compared to women in their youth, women in their middle age may reduce their physical activity by up to $40 \%[5,6]$. During perimenopausal age, this can intensify side effects of menopause, manifested by a reduction in the basal metabolic rate and loss of muscle mass among 
other effects, all of which also contribute to the risk of obesity [7].

A moderate to high level of physical activity in middle-aged women decreases blood pressure and the overall level of triglycerides together with increasing beneficial HDL cholesterol; it also decreases the level of glucose in the blood and prevents excessive weight gain, which makes physical activity a crucial protective factor against metabolic syndrome [8]. Intense and frequent physical activity of middle-aged women has a beneficial influence on muscle strength and helps to protect bone density [9]. Increased physical activity of women in middle age has a significant positive impact on their sexual functioning $[10,11]$. A 12-year observation of residents of Helsinki revealed that among those of middle age, with an increase in the frequency and intensity of physical activity performed during leisure time, the risk of sudden and early death decreases [12]. Therefore, if an increasing number of empirical studies confirms positive health results of physical activity for middle-aged women, it naturally begs the question: why, despite knowledge of its health benefits, do so many individuals not undertake any physical activity? [13-15]. Breuer et al. distinguish four factors that cause a decrease in physical activity with age, namely, decrease in the fitness level and health (physical factor), change in motivation and attitude towards activity (psychological factor), socially acceptable norms of behaviour (social factor), and changes to the economic resources associated with age (economical factor) [16]. The KCS Scale, a research tool used to measure kinesiophobia [17, 18], mentions the Breuer factors. However, they are not treated as time categories (i.e. decreasing physical activity with age), but rather as activity determinants that can create barriers [17]. An example of a barrier to physical activity can be kinesiophobia, that is, a relatively constant psychological disposition conditioned by both biological and psychological factors. Kinesiophobia, treated as a personality disposition, is classified into the category of avoidance behaviours, and authors of this publication claim that it should be treated not solely as a barrier against pain, but much more broadly: as a fear of the feeling of physical and/or psychological discomfort as a consequence of physical activity.

\section{Aim of the study}

So far, there have been few articles on analysis of the physical activity barriers of women of perimenopausal age, including the evaluation of kinesiophobia and its conditions; thus, the purpose of this publication is to investigate possible links between biological and psychological domains of concerns regarding the movement, physical activity and fitness of women between the ages of 48 and 58.

\section{Material and methods}

\section{Participants}

The study included 105 women between the ages of 48 and 58, residents of the Silesia province in Poland. Criteria for inclusion in the study included age (48-58), medical contraindications to perform moderately intense physical activity, and permission to participate in the study. The characteristics of examined women are presented in Table I.

All procedures associated with the study were performed in accordance with the Helsinki Declaration of 1975 , modified in 1983 . The women studied were informed of the objective of the study and its course, and advised that they could refuse to participate in the studies without stating the reason. All participants consented to the processing of their personal data to the extent required for conducting the study in a manner that prevented their identification by others. Consent was obtained from the University Bioethics Committee for Scientific Studies, which was included in Resolution No. 10/2013 dated 21 November 2013.

Data collection involved two different stages. In the first stage, participants filled in questionnaires that evaluated the level of barriers to physical activity and the actual level of physical activity. In the second stage, measurement of basic anthropometric parameters (height and weight) was performed and the fitness level was assessed.

\section{Evaluation of the barriers to physical activity}

Barriers to physical activity were assessed using the Kinesiophobia Causes Scale (KCS) questionnaire [17]. This questionnaire includes 20 closed questions. Answers to these questions are scored on a scale of 0 to 100 - the higher the score obtained, the greater the intensification of barriers to activity (i.e. kinesiophobia). Answers to the first ten questions form the Biological Domain (BD) and the remaining 10 form the Psychological Domain (PD). Each domain contains four factors. For the $\mathrm{BD}$, the factors are morphologic, individual need for stimulation, energetic substrates, and

Tab. I. Demographic data of the participants

\begin{tabular}{lccc}
\hline Features & $n$ & x; SD & Min. - Max. \\
\hline $\begin{array}{l}\text { Age } \\
\text { [years] }\end{array}$ & 105 & $52.7 \pm 2.9$ & $48-58$ \\
\hline $\begin{array}{l}\text { Weight } \\
{[\mathrm{kg}]}\end{array}$ & 105 & $69.4 \pm 7.8$ & $54-86$ \\
\hline $\begin{array}{l}\text { Height } \\
{[\mathrm{cm}]}\end{array}$ & 105 & $163.0 \pm 5.8$ & $150-178$ \\
\hline $\begin{array}{l}\mathrm{BMI} \\
{\left[\mathrm{cm} / \mathrm{kg}^{2}\right]}\end{array}$ & 105 & $26.3 \pm 3.7$ & $20.19-34.22$ \\
\hline
\end{tabular}


power of biological driver. PD also contains four factors, namely self-acceptance, self-assessment of motor predispositions, state of mind, and susceptibility to social influence. The score for the domain is the mean value of the sum of the factors that create that domain, whereas the overall index of kinesiophobia (KCS) is the mean value of two domains $[17,18]$.

\section{Evaluation of physical activity}

The level of habitual physical activity was estimated using Baecke questionnaire (SEWL - Subjective Experience of Work Load) [19]. Baecke questionnaire of the activity is used for the subjective evaluation of the activity of the examined individual. It includes two open questions related to the occupation and type of sport performed, and fourteen closed questions. The closed questions are related to the frequency of performance of those activities and the physical strain. Answers to these questions are given in simple adverbial forms (never, seldom, sometimes, often, always; or significantly less, less, the same, greater, significantly greater) and are ranked on a scale 1-2-3-4-5. This form of questionnaire allows for evaluation of the respondent's level of physical activity in three different areas of activity: occupation (Work Physical Activity Index - WPAI), sport and recreation activity (Sport Activity Index - SAI) and leisure-time physical activity not related to sport (Leisure-time Physical Activity Index - LPAI). The sum of these areas of activity allows to define global habitual physical activity (Habitual Physical Activity Index - HPAI) [19, 20].

\section{Evaluation of fitness level}

The modified Fullerton Functional Fitness Test was used for the evaluation of physical activity [21]. This test was composed of 5 trials, which included the evaluation of the following areas: strength endurance of the upper body (Arm Curl) and lower body (30-second Chair Stand), upper body flexibility (Back Scratch) and lower body flexibility (Chair Sit-and-Reach), and 6-minute-long walk test (6-minute walk). In both strength trials, the number of correctly performed trials was taken into account for further analysis (the arm curl and its supination for the upper body, and a full cycle from the sitting position through standing to re-sitting on the chair for the lower body) for 30 seconds. In the flexibility trials, the indirect measurement was the distance between tips of middle fingers (upper body flexibility trial) and the tip of the middle finger and toes of the foot of the dominant leg (lower body flexibility trial). In both flexibility trials, the measurements were taken using a rigid tailor measuring tape with the accuracy of $0.5 \mathrm{~cm}$. The following was assumed to be the normal value ("0"): touching with the middle fingertip of the right hand the middle fingertip of the left hand (upper body) and fingertips touching the toes (lower body). Any deficit was expressed as a negative number, and an outcome better than normal was expressed in positive numbers. The last trial tested the greatest distance (expressed in metres) walked along a $20 \times 4$-metre rectangle during a 6-minute walk.

\section{Statistical analysis}

The evaluation of the reliability of the KCS questionnaire was performed by examining the test-retest reliability (evaluation of the compatible responses after one month with the test-retest reliability method) and analysing internal consistency (Cronbach's $\alpha$ ), where all final questions that created the biological and psychological domains of the KCS questionnaire were separately included. The values of Cronbach's $\alpha$ above 0.70 were assumed to be the scale of the acceptable reliability [22]. Relationships between variables were calculated using Pearson's linear correlation test. The statistically significant critical value was $p \leq 0.05$.

\section{Results \\ Reliability of KCS}

Figure 1 demonstrates percentage values of compatible responses between the first and second assessment for all included in the questionnaire questions. Except for question number 2 (79\% of compatible responses), at least $80 \%$ compatibility of answers existed for the questions included in the questionnaire after 30 days.

The Biological Domain is created from questions 1 to 11 , whereas the Psychological Domain includes questions 12 to 20 of the KCS questionnaire. In both cases, the internal consistency turned out to be sufficiently high ( $n=97$; Cronbach's $\alpha=0.788$ for the Biological Domain and $n=97$; Cronbach's $\alpha=0.769$ for the Psychological Domain) to justify their use as composites.

\section{Physical activity and fitness}

Women examined had a relatively average level of physical activity (Table II). The mean values of the physical activity index during work and in leisure time were slightly above half on the adopted scale. However, the mean value of the sport and recreation activity index was significantly below half on the adopted scale. The minimum and maximum values indicate large individual distinguishing women with a high level of physical activity during their work, who are also very physically active in their leisure time, from women with a minimal physical activity level during work, and who spend their leisure time passively.

Results of the modified Fullerton Fitness Test indicate large individual diversification of the physical activity of 


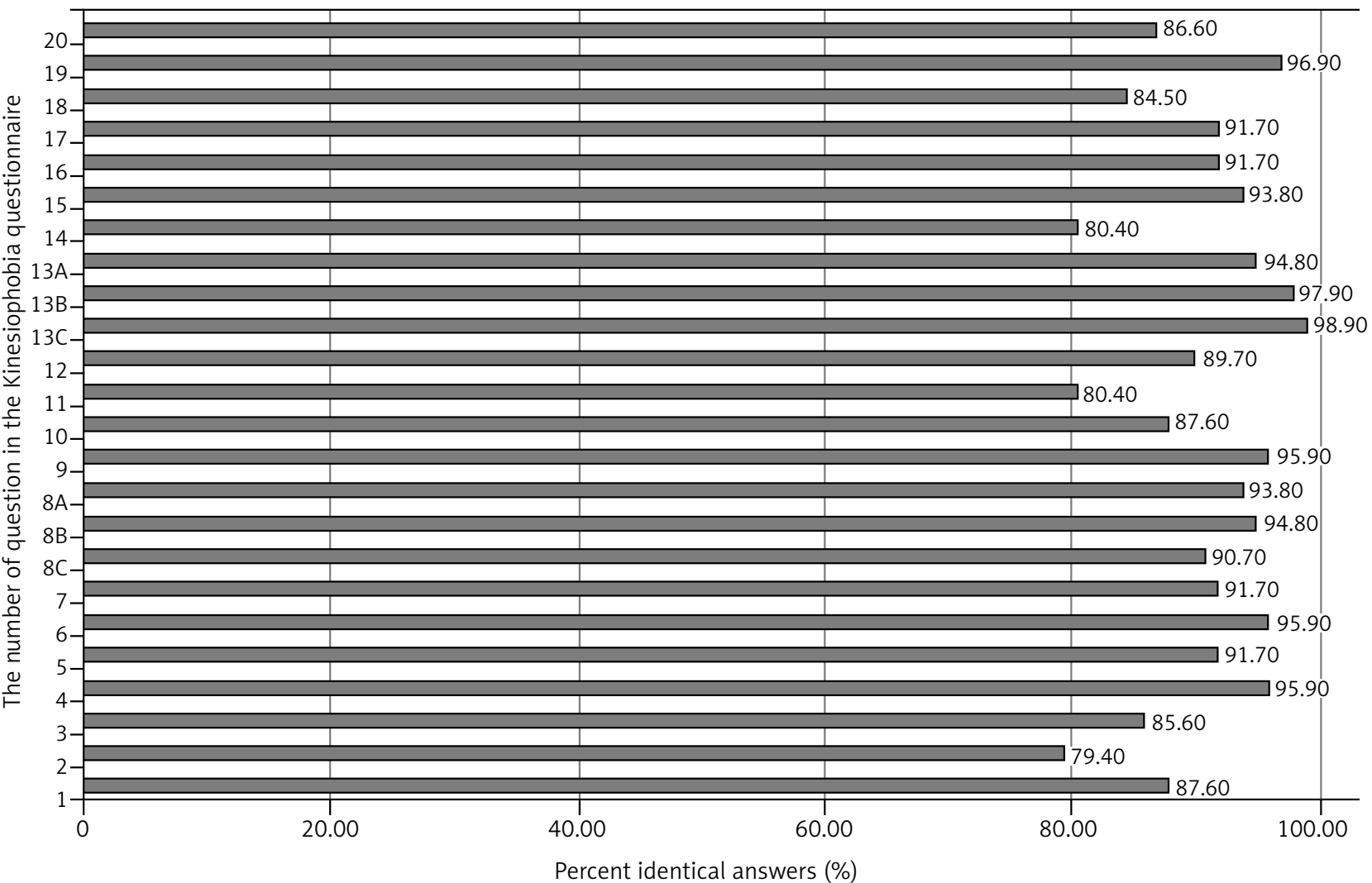

Fig. 1. Percentage of identical answers to individual questions of the KCS questionnaire

Tab. II. Data of physical activity index of the participants

\begin{tabular}{lccc}
\hline Index of physical activity & $n$ & x; SD & Min. - Max. \\
\hline In work & 105 & $2.74 \pm 0.9$ & $1.0-4.25$ \\
\hline Sport & 105 & $2.02 \pm 0.7$ & $1.0-4.0$ \\
\hline In leisure time & 105 & $2.69 \pm 0.9$ & $1.0-4.25$ \\
\hline Habitual & 105 & $7.44 \pm 1.6$ & $\begin{array}{c}4.875- \\
10.375\end{array}$ \\
\hline
\end{tabular}

Tab. III. The results of Fullerton Fitness Test of the participants.

\begin{tabular}{lccc}
\hline Features & $n$ & x; SD & Min. - Max. \\
\hline Upper body strength & 105 & $15.2 \pm 3.0$ & $9-24$ \\
\hline Lower body strength & 105 & $14.1 \pm 3.2$ & $9-25$ \\
\hline Upper body flexibility & 105 & $-4.2 \pm 5.8$ & $-16.0-10.0$ \\
\hline Lower body flexibility & 105 & $-1.0 \pm 6.4$ & $-22.5-18.0$ \\
\hline 6-minute walk & 105 & $527.1 \pm 61.4$ & $450-773$ \\
\hline
\end{tabular}

women examined in the study (Table III). Mean values of the trials are as follows: upper and lower body strength and 6-minute walk corresponded with approx. 56.4-68.2\% maximum values of results obtained in the examined population. However, the mean values of both flexibility trials clearly indicate functional deficits in upper and lower body flexibility in the majority of women examined.
Tab. IV. Results of the KCS questionnaire

\begin{tabular}{lccc}
\hline $\begin{array}{l}\text { Components of } \\
\text { kinesiophobia factors }\end{array}$ & $n$ & x; SD & Min. - Max. \\
\hline Morphologic & 105 & $22.4 \pm 21.9$ & $8-62.5$ \\
\hline $\begin{array}{l}\text { Individual need for } \\
\text { stimulation }\end{array}$ & 105 & $48.7 \pm 17.4$ & $8.3-83.3$ \\
\hline $\begin{array}{l}\text { Energetic substrates } \\
\text { Power of biological } \\
\text { drivers }\end{array}$ & 105 & $31.7 \pm 22.8$ & $0-91.7$ \\
\hline $\begin{array}{l}\text { Biological Domain } \\
\text { Self-acceptance }\end{array}$ & 105 & $35.6 \pm 25.0$ & $0-87.5$ \\
\hline $\begin{array}{l}\text { Self-assessment of } \\
\text { motor predispositions }\end{array}$ & 105 & $57.1 \pm 31.7$ & $2.08-66.7$ \\
\hline State of mind & 105 & $51.3 \pm 23.9$ & $0-100$ \\
\hline $\begin{array}{l}\text { Susceptibility to social } \\
\text { influence }\end{array}$ & 105 & $69.0 \pm 23.7$ & $0-100$ \\
\hline $\begin{array}{l}\text { Psychological Domain } \\
\text { KCS Total Score }\end{array}$ & 105 & $53.3 \pm 17.1$ & $9.38-85.42$ \\
\hline
\end{tabular}

\section{Results of KCS questionnaire}

The results of the KCS questionnaire for the examined female population indicate a larger share of PD in the KCS total score (Table IV). SD analysis also indi- 
Tab. V. Correlation between the results of the KCS questionnaire and physical activity index

\begin{tabular}{|c|c|c|c|c|}
\hline & $\begin{array}{c}\text { Habitual Physical } \\
\text { Activity Index (HPAI) }\end{array}$ & $\begin{array}{c}\text { Work Physical Activity } \\
\text { Index (WPAI) }\end{array}$ & $\begin{array}{c}\text { Sport Activity Index } \\
\text { (SAI) }\end{array}$ & $\begin{array}{l}\text { Leisure-time Physical } \\
\text { Activity Index (LPAI) }\end{array}$ \\
\hline Morphologic & $-0.340^{\star \star \star}$ & -0.185 & -0.026 & $-0.382^{\star * \star}$ \\
\hline $\begin{array}{l}\text { Individual need for } \\
\text { stimulation }\end{array}$ & $-0.457^{\star \star *}$ & -0.149 & $-0.357^{\star \star *}$ & $-0.364^{\star \star \star}$ \\
\hline Energetic substrates & $-0.530^{\star \star *}$ & -0.073 & $-0.365^{\star \star *}$ & $-0.597^{\star \star \star}$ \\
\hline $\begin{array}{l}\text { Power of biological } \\
\text { drivers }\end{array}$ & $-0.552^{\star * *}$ & -0.180 & $-0.326^{\star \star *}$ & $-0.542^{\star * \star}$ \\
\hline Biological Domain & $-0.581^{\star \star *}$ & 0.180 & $-0.328^{\star \star *}$ & $-0.589^{\star \star \star}$ \\
\hline Self-acceptance & 0.160 & 0.080 & 0.033 & 0.180 \\
\hline $\begin{array}{l}\text { Self-assessment of mo- } \\
\text { tor predispositions }\end{array}$ & $-0.392^{\star * *}$ & $-0.216^{\star}$ & $-0.285^{\star *}$ & $-0.264^{\star *}$ \\
\hline State of mind & $-0.598^{\star \star *}$ & -0.092 & $-0.504^{\star \star \star}$ & $-0.576^{\star \star \star}$ \\
\hline $\begin{array}{l}\text { Susceptibility to social } \\
\text { influence }\end{array}$ & $-0.515^{\star * *}$ & 0.061 & $-0.626^{\star * *}$ & $-0.515^{\star \star *}$ \\
\hline Psychological Domain & $-0.451^{\star * *}$ & -0.049 & $-0.483^{\star \star *}$ & $-0.386^{\star \star \star}$ \\
\hline KCS Total Score & $--0.577^{\star \star \star}$ & -0.129 & $-0.451^{\star \star *}$ & $-0.545^{\star \star \star}$ \\
\hline
\end{tabular}

${ }^{*} p<0.05 ;{ }^{* *} p<0.01 ;{ }^{* * *} p<0.001$

Tab. VI. Correlation between the results of the KCS questionnaire and results of Fullerton Fitness Test

\begin{tabular}{|c|c|c|c|c|c|}
\hline & $\begin{array}{l}\text { Upper body } \\
\text { strength }\end{array}$ & $\begin{array}{l}\text { Lower body } \\
\text { strength }\end{array}$ & $\begin{array}{l}\text { Upper body } \\
\text { flexibility }\end{array}$ & $\begin{array}{l}\text { Lower body } \\
\text { flexibility }\end{array}$ & $\begin{array}{c}\text { 6-minute } \\
\text { walk }\end{array}$ \\
\hline Morphologic & -0.132 & $-0.281^{\star *}$ & $-0.306^{\star *}$ & -0.066 & -0.134 \\
\hline Individual need for stimulation & $-0.341^{\star * *}$ & -0.126 & $-0.359^{* \star *}$ & $-0.429^{\star \star \star}$ & $-0.250^{* *}$ \\
\hline Energetic substrates & $-0.398^{\star * *}$ & $-0.400^{\star * *}$ & $-0.445^{\star * *}$ & $-0.256^{\star *}$ & $-0.322^{* * *}$ \\
\hline Power of biological drivers & -0.174 & $-0.259^{* *}$ & $-0.304^{* *}$ & -0.037 & -0.157 \\
\hline Biological Domain & $-0.315^{\star *}$ & $-0.338^{\star * *}$ & $-0.434^{\star \star *}$ & $-0.222^{*}$ & $-0.262^{\star *}$ \\
\hline Self-acceptance & $-0.332^{* * *}$ & $-0.236^{*}$ & 0.007 & -0.150 & $-0.319^{\star *}$ \\
\hline Self-assessment of motor predispositions & $-0.353^{\star * *}$ & $-0.242^{*}$ & $-0.376^{\star \star *}$ & $-0.438^{\star \star *}$ & $-0.449^{\star * *}$ \\
\hline State of mind & $-0.543^{\star * *}$ & $-0.246^{*}$ & $-0.589^{\star \star \star}$ & $-0.326^{\star \star *}$ & $-0.385^{\star * *}$ \\
\hline Susceptibility to social influence & $-0.372^{\star * \star}$ & $-0.239^{*}$ & $-0.357^{\star \star *}$ & $-0.503^{\star \star *}$ & $-0.319^{\star *}$ \\
\hline Psychological Domain & $-0.598^{\star * *}$ & $-0.361^{\star \star \star}$ & $-0.461^{\star \star \star}$ & $-0.524^{\star \star \star}$ & $-0.548^{\star \star \star}$ \\
\hline KCS Total Score & $-0.507^{\star \star \star}$ & $-0.390^{\star * \star}$ & $-0.499^{\star \star \star}$ & $-0.413^{\star \star \star}$ & $-0.449^{\star * \star}$ \\
\hline
\end{tabular}

cates the greatest individual diversification of the morphologic parameter in BD and self-acceptance in PD.

\section{Impact of physical activity and fitness on the level of kinesiophobia}

Analysis of the correlation between the Baecke and KCS questionnaires indicated a statistically significant relationship between HPAl and all parameters that form BD (Table V). The strongest recorded correlation was the correlation with the power of biological driv- er $(r=-0.552)$. As a result, an explicit correlation between HPAl and DB $(r=-0.581)$ was recorded. Negative values of the correlation indicate that those individuals who have a low level of habitual physical activity are also characterised by a high level of kinesiophobia conditioned by biological factors. It is interesting that there is no significant relationship between the level of WPAI and components of this domain with BD itself. However, among PD parameters the strongest correlation with HPAI was recorded for the state of mind $(r=-0.598)$. Among component indicators that form 
HPAl, the strongest correlation was recorded between SAI and susceptibility to social influence $(r=-0.626)$. Analogously to $\mathrm{BD}$, a negative correlation was also recorded that indicates a negative impact of the low level of physical activity on the level of kinesiophobia, conditioned by psychological factors. Except for a low correlation with self-assessment of motor predispositions ( $r=-0.216)$, correlations of WPAI in that domain were not statistically significant. Also, no relationship was found between self-acceptance and the HPAl index and its components. HPAI had a negative correlation on the moderate level with the KCS total score $(r=-0.577)$, while LPAI had a slightly higher negative impact on the KCS total score value $(r=-0.545)$.

Results of the Fullerton Fitness Test were inversely correlated with the KCS questionnaire results (Table VI). It indicates that less physically fit women are characterised by higher levels of kinesiophobia. Slightly stronger correlations between fitness trials of the Fullerton Fitness Test were recorded in relation to PD. The strongest correlation with the components forming the biological domain and with the BD itself was the results of the upper body flexibility trial ( $r=$ from -0.304 to -0.445 ). The strongest correlation between the components forming the psychological domain and the PD itself was recorded in relation to the results of the upper body strength and 6-minute walk trials ( $r=$ from -0.319 to -0.589). The results of upper body strength and upper body flexibility trials ( $r=-0.507$ and -0.499 , respectively) had the greatest negative impact on the overall level of kinesiophobia in the KCS total score.

\section{Discussion}

There are several groups of factors conditioning the level of physical activity: from demographic and biological, through psychological, cognitive, emotional, social and cultural, to the elements of fitness and abilities [23]. Some authors highlight the role of social encouragement in engaging in physical activity [24] or the meaning of self-efficacy in terms of engaging in physical activity and the effects of that physical activity [25]. It is also important to mention psychosocial factors underlying physical activity [26]. Moreover, the unusual complexity of human behaviour and its determinants should be mentioned along with these numerous reports. All these facts may contribute to the impression that when discussing this topic in research, it is hard or impossible to make estimates or draw conclusions. Nevertheless, the importance of this issue and a pro-health impact of physical activity motivates the need to seek the causes of barriers against engaging in this type of activity.

The results of this study support the theory that barriers to activity are caused by kinesiophobia, which is understood as a barrier against discomfort as a consequence of physical activity $[17,18]$. It is interesting that a strong negative impact was recorded in relation to non-occupational physical activity, both sport and non-sport forms of physical activity in leisure time. For women examined in the study, their physical activity associated with performance of professional duties correlates weakly only with self-assessment of motor predispositions amongst all components of the KCS questionnaire. This fact requires further analysis and research, not only regarding the evaluation of the type of occupation, but also factors such as habits and routine. The women examined were of middle age, thus they had long-term working experience and their family life structure shaped their activities around other, more family-oriented aspects of life (e.g. raising children) than the activities typically associated with younger and/or single/childless women. In other words, women examined in the study were at the stage of their lives where their job has become a strong motivator for actions related to the need for self-realisation and self-acceptance, and does not necessarily have to be considered negatively as an obligation or forced by life circumstances. Results of the impact of non-occupational physical activity are the opposite to some extent. In terms of sport activity, only two cases did not achieve a statistically significant correlations (morphologic from BD and self-acceptance from PD), and in terms of non-sport physical activity, only the parameter of self-acceptance from PD did not achieve a statistically significant correlation. It is interesting, and may have a practical importance, that a low level of sport activity has a stronger correlation with PD and a low level of non-sport physical activity in leisure time has a stronger correlation with BD. Means of locomotion (walking, cycling) and a decrease in passive forms of leisure time activities (e.g. watching TV) have a significant impact on the biological components of kinesiophobia. On the other hand, sport significantly impacts on the psychological components of kinesiophobia. Physically active women of perimenopausal age have higher self-esteem and are less prone to barriers to sport-related physical activities conditioned by their surrounding environment. Popularisation of sport can also be treated as a factor which reduces negative psychological effects that accompany the menopausal period and manifest as low self-esteem, among others. Taking into account the fact that physical activity was evaluated subjectively by the examined women, the results related to the correlations between the fitness level and the level of kinesiophobia are even more interesting. The results of all fitness trials significantly impact on the level of kinesiophobia. Similarly to low physical activity, a low level of fitness also negatively impacts on the level of barriers against activity. The level of fitness has a stronger negative impact on PD than on $\mathrm{BD}$ in all trials. The strongest correlations were in trials assessing upper body strength, 6-minute walk 
and upper body flexibility. In terms of BD with regard to kinesiophobia, the strongest negative impact was seen in the results of upper body flexibility, lower body strength and upper body strength. The morphologic and power of biological driver parameters from BD, and the self-acceptance of kinesiophobia parameter from PD, were the least likely to be associated with a level of fitness. As a result, all trials of the Fullerton Fitness Test had a moderate but at the same time negative impact on the KCS total score level. Quite interesting is a relatively strong negative impact of the low level of upper body strength and upper body flexibility on the KCS total score. This could possibly be associated with the social role assigned to middle-aged women in traditional Polish culture, where the efficiency of upper limbs has a critical importance. In other words, the strength and flexibility of the upper body has an influence on the efficiency related to the utilitarian skills necessary for housekeeping (e.g. shopping, cooking, cleaning, doing laundry) and hygiene and care activities (e.g. dressing, taking a bath, brushing hair, doing make-up). However, at this stage, there are only speculations that require a comparative study with a male population within the same age bracket.

Results of this study are not comparable with results of other authors as this study is not only the first trial of this type in terms of examining women of perimenopausal age, but also the first trial connecting physical activity and fitness with a level of kinesiophobia. Typical symptoms of barriers against physical activity rarely occur due to the fact that lack of physical activity is included in the category of avoidance behaviours. In the case of physical activity, there are more or less conscious reactions of rationalisation ("lack of time", "lack of immediate results"), denial (erasing the need for physical activity from consciousness) or simulated reactions (e.g. cheering). As recently highlighted, the lack of motivation could be an important barrier in engaging in physical activity. It relates to a complete lack of motivation, to a not sufficiently high level of motivation or to external motivation. In each case, it forms a barrier to engagement in systematic physical activity. Conditions related to motivation became a self-determination theory [27]. This theory originated from the macro-theory of human needs and the self-determination of behaviour [28]. This theory includes two ways of motivation - intrinsic and extrinsic. The first type of motivation is a satisfaction from undertaking activities, which in terms of physical activity means the feeling of pleasure of being active, feeling of satisfaction or even enjoyment from "exercising" of one's skills, feeling of personal accomplishment or even excitement. External motivation refers to the activity undertaken due to instrumental reasons or to achieve other results in addition to being active. For instance, the external motivation occurs when the individual engages in physical activity to obtain a material or social reward or to avoid disapproval from the social environment [27]. The feeling of satisfaction associated with the self-determination theory is one of the basic psychological needs of humans. In terms of physical activity, satisfaction is a result of the improvement of vitality and a feeling of well-being [29]. In relation to the results presented in this publication, kinesiophobia is a feature significantly associated with physical activity and fitness. In relation to the self-determination theory, a high level of kinesiophobia can become a significant emotional barrier determining one's intrinsic motivation to be physically active. Interactions between a low level of physical activity (and an associated reduction in fitness) and a high level of kinesiophobia are becoming the barrier to engagement in physical activity and are creating a "vicious cycle". In that mechanism, the passive activity does not promote the formation of coordination and conditioning of motor abilities. As a result, the following conviction occurs: "Because I am less fit, thus I am afraid to engage in physical activity that requires this fitness". From a psychological point of view, the barriers against emotionally negative experiences such as ridicule, embarrassment or humiliation can be strengthened. Therefore, assessment of the level of kinesiophobia can have significant practical implications oriented at individual programming of means and forms of physical activity. Such a program should include not only physical abilities and predispositions, but also individually changeable emotional sensitivity expressed through different levels of barriers against movement (kinesiophobia), among others. In that way negative implications of physical activity can be minimised, and the possibility of achieving a feeling of satisfaction from being physically active can be promoted. For women of perimenopausal age, they can experience not only the health benefits of being physically active, but also the positive emotions that accompany that activity.

\section{Conclusions}

Physical activity and fitness of women between the ages of 48 and 58 are significantly associated with kinesiophobia levels. Low levels of physical activity and fitness in women of perimenopausal age favour a kinesiophobic attitude and therefore increase the level of barriers against engaging in physical activity.

\section{Disclosure \\ Authors report no conflict of interest.}

\section{References}

1. Eurobarometer: Sport and Physical Activity. Special Eurobarometer 2010; 334/Wave 72.3. 
2. Special Eurobarometer 412 "Sport and Physical Activity". [http:// ec.europa.eu/public_opinion/archives/ebs/ebs_412_en.pdf].

3. Colley RC, Garriguet D, Janssen I, et al. Physical activity of Canadian Adults: Accelerometer data from the 2007 to 2009 Canadian Health Measures Survey. Statistics Canada, Health Reports 2011, 22, Catalogue no. 82-003-XPE.

4. Macías R, Garrido-Muñoz M, Tejero-González CM, et al. Prevalence of leisure-time sedentary behavior and sociodemographic correlates: a cross-sectional study in Spanish adults. BMC Public Health 2014; 14: 972

5. Elavsky S. Physical activity, menopause, and quality of life: the role of affect and self-worth across time. Menopause 2009; 16: 265-271.

6. Evenson K, Wilcox S, Pettinger M, et al. Vigorous leisure activity through women's adult life. Am J Epidemiol 2002; 156: 945-953.

7. Lovejoy JC. Weight gain in women at midlife: the influence of menopause. Obesity Manage 2009; April: 52-56.

8. Lin $\mathrm{CH}$, Chiang SL, Yates P, et al. Moderate physical activity level as a protective factor against metabolic syndrome in middle-aged and older women. J Clin Nurs 2015; 24: 1234-1245.

9. Chachal J, Lee R, Luo J. Loading dose of physical activity is related to muscle strength and bone density in middle-aged women. Bone 2014 67: 41-45.

10. Cabral PU, Canário AC, Spyrides MH, et al. Physical activity and sexual function in middle-aged women. Rev Assoc Med Bras 2014; 60: 47-52.

11. Dąbrowska J, Drosdzol A, Skrzypulec V, Plinta R. Physical activity and sexuality in perimenopausal women. Eur J Contracept Reproduct Health Care 2010; 15: 423-432.

12. Lahti J, Holstila A, Lahelma E, Rahkonen O. Leisure-time physical activity and all-cause mortality. PLOS One 2014; 9: e101548.

13. Drygas W, Kwaśniewska M, Kaleta D, Ruszkowska-Majzel J. Increasing recreational and leisure time physical activity in Poland - how to overcome barriers of inactivity. Journal of Public Health 2008; 16: 31-36.

14. La Fontaine T. Physical Activity: The Epidemic of Obesity and Overweight Among Youth: Trends, Consequences, and Interventions. Am J Lifestyle Med 2008; 2: 30-33.

15. Martin BW. Physical activity behavior in the Swiss population: what do we know in 2010? Revue Medicale Suisse 2010; 6: 1489-1494.

16. Breuer C, Hallmann K, Wicker P, Feiler S. Socio-economic patterns of sport demand and ageing. European Review of Aging and Physical ACtivity 2010; 7: 61-70.

17. Knapik A, Saulicz E, Gnat R. Kinesiophobia - Introducing a New Diagnostic Tool. J Hum Kinet 2011; 28: 25-31.

18. Knapik A, Saulicz E, Kuszewski M, et al. Gender and level of kinesio phobia in adult population of southern Poland. Medical Journal of the Rzeszow University and the National Medicines Institute 2012; 10: 277 287.

19. Baecke JA, Burema J, Frijtes JE. A short questionnaire for the measurement of habitual physical activity in epidemiological studies. Am J Clin Nutr 1982; 36: 936-942.

20. Ono R, Hirata S, Yamada M, et al. Reliability and validity of the Baecke physical activity questionnaire in adult women with hip disorders. BMC Musculoskeletal Disorders 2007; 8: 61.

21. Różańska-Kirschke A, Kocur P, Wilk M, Dylewicz P. The Fullerton Fitness Test as an index in the elderly. Med Rehabil 2006; 10: 15-19.

22. Hair J, Black W, Babin B, et al. Multivariate Data Analysis (6th ed.). Pearson Educational Inc., New Jersey 2006.

23. Sallis JF, Owen N. Physical Activity and Behavioral Medicine. Thousand Oaks, Sage 1999; 110-133.

24. Martin-Matillas M, Ortega FB, Ruiz JR, et al. Adolescent's physical activ ity levels and relatives' physical activity engagement and encouragement: the HELENA study. Eur J Public Health 2010; 21: 705-712.

25. McAuley E, Blissmer B. Self-efficacy determinants and consequences of physical activity. Exerc Sport Sci Rev 2000; 28: 85-88.

26. Zhang J, Middlestadt SE, Ji Ch. Psychosocial factors underlying physical activity. Int J Behav Nutr Phys Act 2007; 4: 38.
27. Teixeira PJ, Carraça EV, Markland D, et al. Exercise, physical activity, and self-determination theory: A systematic review. Int J Behav Nutr Phys Act 2012; 9: 78.

28. Deci EL, Ryan RM. The "what" and "why" of goal pursuits: Human needs and the self-determination of behavior. Psychological Inquiry 2000, 11: 227-268.

29. Ryan RM, Deci EL. Overview of self-determination theory: An organismic dialectical perspective. In Handbook of Self-Determination Research. Deci EL, Ryan RM (eds.). Rochester University Press, Rochester 2002: 3-33. 